\title{
Healthcare Experience and their Relationship with Demographic, Disease and Healthcare-Related Variables: A Cross-Sectional Survey of Patients with Chronic Diseases Using the IEXPAC Scale
}

\author{
Domingo Orozco-Beltrán ${ }^{1}$ Javier de Toro ${ }^{2}$. María J. Galindo ${ }^{3}$ - Ignacio Marín-Jiménez ${ }^{4}$ - Francesc Casellas ${ }^{5}$. \\ María J. Fuster-RuizdeApodaca ${ }^{6}$ - María L. García-Vivar ${ }^{7}$. Antonio Hormigo-Pozo ${ }^{8} \cdot$ Mercedes Guilabert $^{9}$. \\ Nuria Sánchez-Vega ${ }^{10} \cdot$ Gonzalo Fernández $^{10} \cdot$ Luis Cea-Calvo $^{10}$
}

Published online: 15 November 2018

(c) The Author(s) 2018

\begin{abstract}
Background Patient experience is acknowledged as a principal aspect of quality healthcare delivery, and it has implications with regard to outcomes.

Objectives Our objective was to evaluate the healthcare experience of patients with chronic diseases to identify patientperceived healthcare gaps and to assess the influence of demographic and healthcare-related variables on patient experiences. Methods A cross-sectional survey was delivered to adult patients with chronic diseases: diabetes mellitus (DM), human immunodeficiency virus (HIV) infection, inflammatory bowel disease (IBD) or rheumatic diseases. Patient experiences were assessed with the Instrument for Evaluation of the Experience of Chronic Patients (IEXPAC) questionnaire, with possible scores ranging from 0 (worst) to 10 (best experience).

Results Of the 2474 patients handed the survey, 1618 returned it (response rate 65.4\%). Patients identified gaps in healthcare related mainly to access to reliable information and services, interaction with other patients and continuity of healthcare after hospital discharge. The mean \pm standard deviation (SD) IEXPAC score was $6.0 \pm 1.9$ and was higher for patients with HIV $(6.6 \pm 1.7)$ than for those with rheumatic disease $(5.5 \pm 2.0)$, IBD $(5.9 \pm 2.0)$ or $\mathrm{DM}(5.9 \pm 1.9)(p<0.001)$. In multivariate models, better overall IEXPAC experience was associated with follow-up by the same physician, follow-up by a nurse, receiving healthcare support from others and treatment with subcutaneous or intravenous drugs. The multivariate model that confirmed patients with HIV or DM had better experience than did those with rheumatic diseases.

Conclusions Through IEXPAC, patients identified aspects for healthcare quality improvements and circumstances associated with better experience, which may permit greater redirection of healthcare toward patient-centered goals while facilitating improvements in social care and long-term healthcare quality.
\end{abstract}

Electronic supplementary material The online version of this article (https://doi.org/10.1007/s40271-018-0345-1) contains supplementary material, which is available to authorized users.

Luis Cea-Calvo

luis.cea@merck.com

Extended author information available on the last page of the article 


\section{Key Points for Decision Makers}

Broad use of the Instrument for Evaluation of the Experience of Chronic Patients (IEXPAC) scale or similar instruments in routine practice with patients with chronic conditions will likely identify and reinforce areas to be pursued to attain continued improvements in healthcare quality.

Patients with chronic diseases should be particularly proactive in steering integrated social care and healthcare toward patient-centered goals.

Further research is now warranted to identify and implement actions to address gaps and clearly define whether IEXPAC score improvements are linked directly with improvements in clinical effectiveness and health-related quality of life in patients with chronic conditions.

\section{Introduction}

Besides clinical effectiveness and safety, patient experience is widely acknowledged as a principal measure of quality healthcare delivery to patients with chronic diseases [1]. The provision of well-planned, proactive and integrated patient-centered care has been associated with enhanced patient experience and clinical outcomes in patients with chronic diseases [2-5]. Indeed, patient experience (e.g., as an inpatient) may involve factors such as attention to analgesia, assistance with feeding, type of environment (e.g., low noise, cleanliness) and dedication of healthcare professionals; all these factors may provide a holistic perspective of overall healthcare quality. Such a perspective may ultimately provide more meaningful information than specific measures of clinical effectiveness and patient safety $[1,6]$.

Quality-of-care improvements over time lead to a more positive experience for patients with chronic conditions [7], and careful measurement of patient experience can provide significant data to facilitate further enhancements in quality of care, clinical effectiveness and patient safety $[1,2]$.

Traditional instruments used for assessing patient experience of chronic care delivery include the Patient Assessment of Chronic Illness Care (PACIC) scale [8] and the Patient Perceptions of Integrated Care (PPIC) survey $[9,10]$. The PACIC scale has been widely used worldwide in various chronic illnesses and has been defined as the most relevant scale for assessing patient perspectives of integrated longterm quality of care $[2,11]$. The PPIC survey evaluates integrated quality of care using a six-dimension model. However, neither PACIC nor PPIC includes aspects relating to developments in information and communications technology in chronic healthcare, and neither directly evaluates interactions between social care and healthcare providers [2].

The Instrument for Evaluation of the Experience of Chronic Patients (IEXPAC; available online at http://www. iexpac.org) was developed recently and has several key advantages over existing instruments for assessing patient experience of chronic care delivery. It focuses on interaction between patients and healthcare teams rather than specific healthcare professionals. It also incorporates a broader notion of integrated care, including social care and patient self-management. Finally, the IEXPAC includes new ways of assessing patient-healthcare interactions using new technologies and patient-patient interactions. Therefore, this instrument can assist in determining the quality of care provided according to the Triple Aim framework (i.e., improving the individual experience of care, improving the health of populations and reducing the per capita costs of care for populations [12]), facilitating reorientation of health system resources from healthcare professionals toward integrated patient-centered care [2].

To gain greater understanding of the potential variables influencing patient experience when measured with the IEXPAC, and potential associations with other important aspects of patient care, we designed a survey that was addressed to patients with one of four different chronic conditions: rheumatic diseases, inflammatory bowel disease (IBD), human immunodeficiency virus (HIV) infection and diabetes mellitus (DM). The current work displays outcomes of the main study objective, namely to assess the healthcare experience of patients with chronic diseases using the IEXPAC, to identify patient-perceived gaps in healthcare and to assess the influence of demographic and healthcare-related variables on patient experience.

\section{Methods}

\subsection{Study Design}

This was a cross-sectional survey of patients with chronic conditions aged $>18$ years who required healthcare on at least two different levels (e.g., primary care and outpatient specialty clinic). Four different patient profiles were selected: patients with rheumatic disease (rheumatoid arthritis or spondyloarthritis) recruited from outpatient hospital clinics, patients with IBD recruited from outpatient hospital clinics, patients with HIV infection recruited from HIV units or internal medicine clinics and patients with DM who also had a diagnosis of cardiovascular or chronic renal disease, selected from primary care clinics. The survey was handed to patients by their physician or nurse. Patients were instructed to read the survey and complete it voluntarily and 
anonymously from home, and then return it by pre-paid mail (see the Electronic Supplementary Material (ESM) 1).

Investigators from the specialties involved in the care of these patients were selected from a wide sample of outpatient hospitals and primary care clinics across the different regions of Spain to be representative of the Spanish healthcare system (ESM 2). To minimize selection bias, each physician or nurse ( 25 from rheumatology teams, 23 from gastroenterology teams and 25 from HIV clinics) handed the survey to the first 25 consecutive patients attending the clinic routinely, regardless of age, sex, disease severity or any other criterion. In addition, 48 primary care physicians each handed the survey to 13 consecutive patients with DM. Surveys were distributed and collected between May and September 2017.

Taking the IEXPAC 2015 (version 11+1) scale as the starting point, a survey was developed for this study with the participation of four physicians expert in the treatment of the abovementioned conditions. The survey was reviewed by members of three patients' associations [the Spanish Association of Patients with Arthritis (CONARTRITIS), the Spanish Association of Patients with Crohn's Disease and Ulcerative Colitis (ACCU) and the Spanish Federation of Patients with Diabetes (FEDE)] and by members of the Spanish AIDS Multidisciplinary Society (SEISIDA), a Spanish Society composed of patients with HIV and different healthcare professionals. Patients reviewed the content and relevance of the questions, and the language used, and suggested modifications or additional questions. Except for validated questionnaires including IEXPAC, which were not modified, suggestions from patients were included in the final version of the survey.

The study was reviewed and approved by the Clinical Investigation Ethics Committee of the Gregorio Marañón Hospital of Madrid, Spain. The study documentation included printed instructions and information for patients about the anonymous nature of the survey and aggregated data processing, which ensured that patient identification was not possible. As agreed by the Clinical Investigation Ethics Committee, the voluntary return of completed questionnaires was taken as implied consent to participate in the study. No clinical data were collected in this study.

\subsection{Survey Instrument}

The survey included multiple-choice questions that provided information about patient demographics, healthcare-related characteristics, disability (Barthel index) [13], follow-up by different specialists or nurses and treatment characteristics (ESM 3). As part of the survey, we included the whole IEXPAC questionnaire verbatim to assess patients' experience with healthcare. The first version (version $11+1$ ), which was used in this study, was developed in 2015 through a comprehensive process of literature review, expert panel work (including healthcare professional and social organizations, experts in quality of healthcare and patients with chronic conditions) and pilot and field work with 356 patients with chronic conditions to assess questionnaire content and face validity and reliability [2].

The IEXPAC scale was designed to be self-administered by patients. It has 11 items, plus an additional item for patients recently hospitalized. The items refer to the previous 6 months, except the question about hospitalization, which refers to the previous 3 years. For each item, patients responded on a 5-point Likert scale, and responses are transformed into scores: always (score 10), mostly (7.5), sometimes (5), seldom (2.5) or never (0). The scale yields an overall score (sum of individual scores for the 11 items divided by 11) between 0 (worst experience) and 10 (best experience) and allows identification of items in which improvement is needed.

Three factors are derived from the first 11 items of IEXPAC. Factor 1 is named "productive interactions" and refers to the characteristics and content of interactions between patients and professionals designed to improve outcomes. The productive interactions score is the average of the scores for items 1, 2, 5 and 9. Factor 2, the "new relational model," refers to new forms of patient interaction with the healthcare system, through the internet or with peers. The score for factor 2 is the average of scores for items 3,7 and 11 . Finally, factor 3, named "patient self-management," refers to the ability of individuals to cope with their diseases, manage their own care and improve their well-being, based on interventions mediated by healthcare professionals. The patient self-management score is the average of scores for items 4 , 6,8 and 10 . The 12 th item refers to continuity after hospitalization and is described separately. The IEXPAC questionnaire showed acceptable internal consistency (Cronbach's $\alpha 0.76)$ and independence among the different factors [2].

\subsection{Statistical Analysis}

The survey was exploratory, and no formal hypothesis or pre-specified sample size was calculated. Conservatively, estimates based on a qualitative variable with $50 \%$ as the expected prevalence, a confidence interval of $95 \%$ and precision of $6 \%$ would give a sample size of 267 patients. Assuming that $15 \%$ of questionnaires would be incorrectly completed by patients, the total sample size for recruitment would be 314 patients. However, the expected response rate also had to be added to permit calculation of the final number of surveys required. Assuming a response rate of $50 \%$, as seen in other surveys handed to patients [14, 15], our survey would have to be handed to approximately 628 patients. As we included four different patient profiles, we planned to 
hand the survey to approximately 2500 patients (625 patients with each background disease).

Descriptive information is displayed as mean \pm standard deviation (SD) for quantitative variables, and as frequencies or percent for qualitative variables. For results of the IEXPAC questionnaire, we calculated the mean \pm SD score for each item, the overall mean \pm SD score and the mean \pm SD scores for the three abovementioned factors. For this calculation, patients without a response to one IEXPAC item were imputed using the mean value of all respondents for that item. Patients lacking a response to more than one item were excluded from this analysis. The distribution of responses to individual items is also displayed, as is the sum of the percent of "always" plus "mostly" responses to each item.

We used Chi-squared or Fisher's exact tests to compare proportions and the Student's $t$ test or analysis of variance (ANOVA) to compare continuous variables. Multiple linear regression models were used to assess the different demographic and healthcare-related variables influencing IEXPAC overall score, and the scores for each factor. Variables that were a priori considered to have the potential to influence patient experience were included in the model. Beta coefficients \pm SD with $p$ values are shown. Given the overall descriptive nature of the results, no multiplicity adjustments were made. There was no imputation for missing data.

\section{Results}

\subsection{Survey Population}

The survey was handed to 2474 patients and was returned by 1618 patients (response rate $65.4 \%$ ). The final sample comprised 359 patients with rheumatic disease $(22.2 \%)$, 341 with IBD (21.1\%), 467 with HIV infection (28.9\%) and 451 with DM (27.9\%). Mean age was $56.2 \pm 14.7$ years, and $59.1 \%$ of patients were male. The principal characteristics of the survey population are shown in Table 1 . Only $6.1 \%$ of patients were affiliated with a patients' association. A total $61.3 \%$ of patients searched for healthcare information from sources other than healthcare providers (i.e., the internet or media).

In terms of healthcare-related characteristics, patients had visited a mean of four specialists (including primary care physician) in the past year, and $19.3 \%$ of patients declared that they sometimes or frequently saw a different treating physician; this value was substantially higher in patients with DM (33.2\%). Regular follow-up by a nurse was reported by $58.0 \%$ of patients overall, with a higher value reported by patients with DM $(82.7 \%)$. Overall, patients were being treated with a mean of 4.7 different medications daily, and $31.1 \%$ of patients were receiving subcutaneous or intravenous medications. During the past 3 years, $48.2 \%$ of patients had been hospitalized, for any reason, at least once.

\subsection{IEXPAC Responses and Experience Scores}

Figure 1 shows the distribution of responses to the 12 IEXPAC items, and mean \pm SD scores, and Table 2 shows the percent of patients who responded "always" or "mostly" according to background disease. Generally, the proportion of patients who responded "always" or "mostly" was high (>70\%) for items related to factors 1 and 3 (i.e., productive interactions and patient self-management), except for item 10 (information about health and social resources), but was low for items related to factor 2 (new relational model). The proportion of patients who responded "always" or "mostly" was especially low $(\leq 15 \%)$ for the items "they help me to get information from the internet," "I can use the internet and my mobile phone to consult my medical records" and "they encourage me to talk to other patients." Only $30.6 \%$ of those who had been hospitalized in the past 3 years received a regular follow-up call or visit after hospital discharge (item 12). For most items, the proportions of patients who responded "always" or "mostly" were higher in patients with HIV infection (Table 2).

Figure 2 shows the distribution of overall IEXPAC experience scores. About $60 \%$ of patients scored between 5 and 8. The mean \pm SD IEXPAC score was $6.0 \pm 1$.9. Scores were higher for productive interactions and patient self-management but lower for the new relational model factor (Table 3). All scores were higher in patients with HIV infection and lower in patients with rheumatic disease (Table 3).

The scores stratified by different demographic and healthcare-related characteristics are displayed as supplementary tables (ESM 4-13). Table 4 shows a summary of the bivariate study. Several scores (overall experience, productive interactions and patient self-management) were slightly higher in males than in females. Scores stratified according to age quartiles were similar, except for the new relational model score (factor 2), which was higher in younger age groups (ESM 5). Patients with fewer specialist visits in the past year, who were usually followed-up by the same physician or who received regular follow-up by a nurse had better overall experience scores. All experience scores were better in patients treated with fewer different medications (Table 4; ESM 12).

\subsection{Multivariate Analysis}

Table 5 shows results from the multiple linear regression models. After adjustment for demographic and healthcarerelated variables, patients with HIV had better experience scores in all cases, and the DM group had higher overall IEXPAC experience, productive interactions and patient 
Table 1 Principal characteristics of survey respondents

\begin{tabular}{|c|c|c|c|c|c|}
\hline Characteristic & All patients $(n=1618)$ & $\begin{array}{l}\text { Rheumatic } \\
\text { disease } \\
(n=359)\end{array}$ & $\operatorname{IBD}(n=341)$ & HIV $(n=467)$ & $\mathrm{DM}(n=451)$ \\
\hline \multicolumn{6}{|l|}{ Patient demographics } \\
\hline Age & $56.2 \pm 14.7$ & $54.6 \pm 13.9$ & $46.8 \pm 12.9$ & $51.6 \pm 10.9$ & $69.5 \pm 10.1$ \\
\hline Sex, men & 59.1 & 36.7 & 51.8 & 73.5 & 67.8 \\
\hline \multicolumn{6}{|l|}{ Educational level achieved } \\
\hline Primary & 42.5 & 43.8 & 30.2 & 42.4 & 50.8 \\
\hline Secondary, including vocational & 34.5 & 32.5 & 32.1 & 35.9 & 28.8 \\
\hline University or further & 23.0 & 23.6 & 27.8 & 21.7 & 20,4 \\
\hline Barthel index $\leq 80$ & 8.2 & 13.1 & 2.1 & 8.3 & 9.0 \\
\hline Affiliated with patients' association & 6.1 & 6.2 & 10.1 & 4.4 & 4.6 \\
\hline $\begin{array}{l}\text { Searched for information about healthcare from sources } \\
\text { other than healthcare providers (i.e., internet, media, } \\
\text { etc.) }\end{array}$ & 61.3 & 67.7 & 73.4 & 59.5 & 48.9 \\
\hline \multicolumn{6}{|l|}{ Healthcare-related characteristics } \\
\hline $\begin{array}{l}\text { Follow-up for healthcare in a Spanish region different } \\
\text { from the patient's main residence }\end{array}$ & 7.2 & 7.9 & 7.8 & 8.8 & 4.4 \\
\hline $\begin{array}{l}\text { Number of different specialists (including primary } \\
\text { care) visited in the past year }\end{array}$ & $4.0 \pm 2.3$ & $4.3 \pm 2.6$ & $3.8 \pm 2.1$ & $3.9 \pm 2.4$ & $4.0 \pm 2.4$ \\
\hline \multicolumn{6}{|l|}{ Patient follow-up } \\
\hline Generally by the same physician & 80.7 & 84.9 & 85.2 & 87.4 & 66.8 \\
\hline Sometimes different & 14.9 & 11.2 & 10.6 & 10.5 & 26 \\
\hline Frequently different & 4.4 & 3.9 & 4.2 & 2.1 & 7.2 \\
\hline Follow-up by a nurse & 58.0 & 49.0 & 44.3 & 51.0 & 82.7 \\
\hline $\begin{array}{l}\text { No support from others (relatives or friends, caregiver) } \\
\text { for healthcare (self-care) }\end{array}$ & 59.1 & 53.2 & 59.2 & 67.9 & 54.8 \\
\hline Number of medicines taken daily & $4.7 \pm 3.2$ & $4.4 \pm 2.6$ & $3.5 \pm 2.4$ & $4.0 \pm 3.4$ & $6.5 \pm 3.2$ \\
\hline Treated with subcutaneous or intravenous medications & 31.1 & 58.5 & 42.2 & 8.4 & 23.9 \\
\hline
\end{tabular}

Data are presented as $\%$ or mean \pm standard deviation unless otherwise noted

All $p<0.05$, except for the item "Follow-up for healthcare in a Spanish region different from the patient's main residence" $(p=0.075)$

$D M$ diabetes mellitus, $H I V$ human immunodeficiency virus, $I B D$ inflammatory bowel disease

self-management scores than patients with rheumatic disease.

A better overall IEXPAC experience score (higher score) was associated with follow-up by the same versus a different physician, follow-up by a nurse, receiving support from others for healthcare rather than self-care and treatment with subcutaneous or intravenous drugs. Follow-up by more specialists in the previous year was associated with a significantly lower overall IEXPAC experience score (Table 5).

Regular follow-up by the same versus a different physician, follow-up by a nurse and treatment with subcutaneous or intravenous drugs were associated with better productive interactions and patient self-management scores. Conversely, more specialist visits in the previous year was associated with worse scores for these two factors. Follow-up by a nurse, support from others for healthcare, younger age and higher educational level achieved were associated with higher new relational model scores. The goodness of fit $\left(R^{2}\right)$ test was low for the four models described $\left(R^{2}\right.$ for the overall IEXPAC score: 0.121, Table 5), suggesting that the model explained only a small part of the variability.

\section{Discussion}

This cross-sectional survey included 1618 patients with chronic diseases, with an approximately even distribution of patients between groups according to background disease: DM, HIV infection, IBD or rheumatic disease. The survey identified several areas to be targeted for potential healthcare quality enhancement in chronically ill patients. For instance, low rates of "always" or "mostly" responses were evident for items relating to assistance in getting information from the internet, ability to use the internet and a mobile phone to access medical records and encouragement to talk to other patients. Indeed, $>60 \%$ of patients searched 


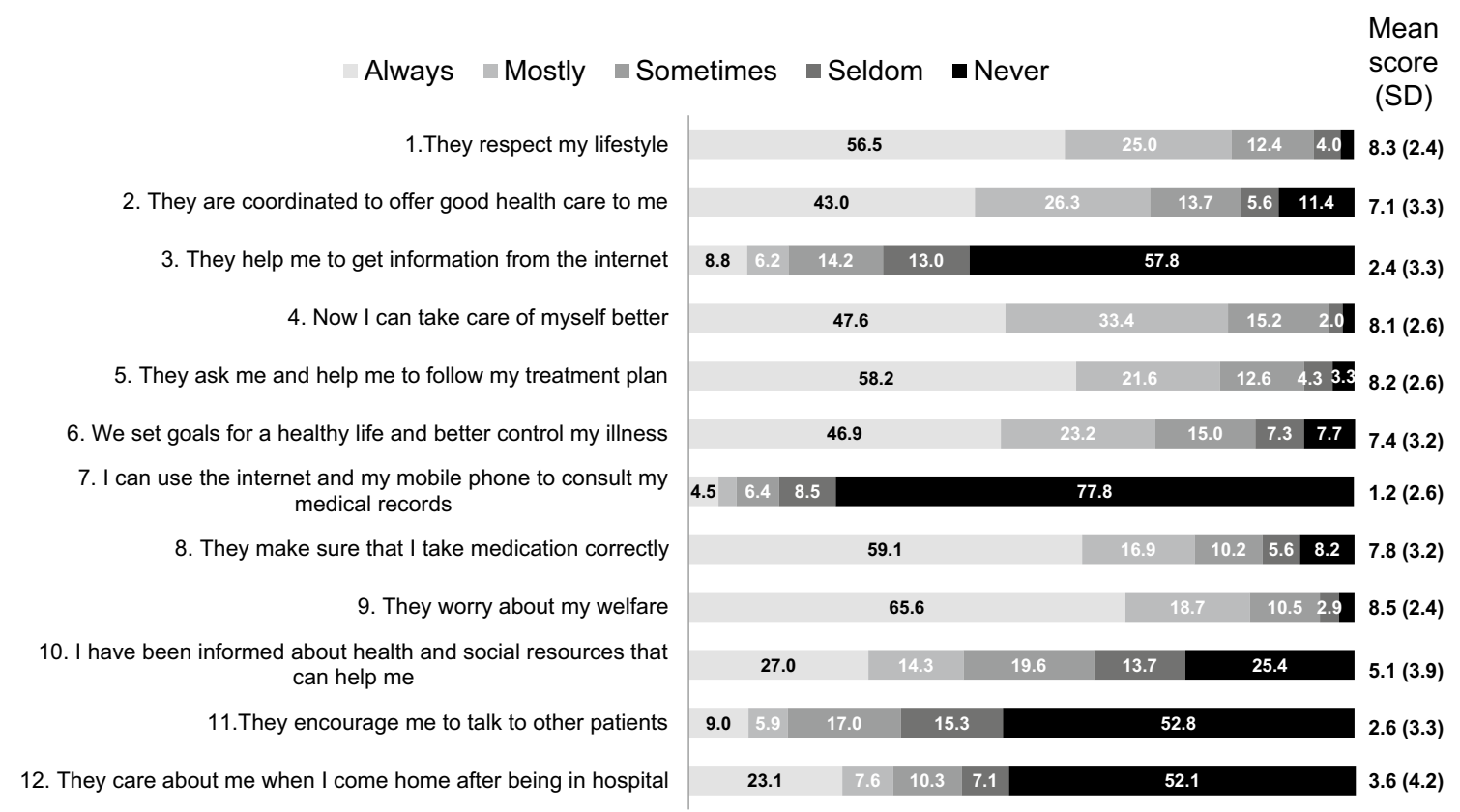

Fig. 1 Frequency distribution of patients' responses to Instrument for Evaluation of the Experience of Chronic Patients (IEXPAC) items. SD standard deviation

for healthcare information from sources other than their healthcare provider (i.e., the internet or media), and only $6.1 \%$ of patients were affiliated with a patients' association to facilitate patient-patient communication, which highlights the importance of implementing actions to guide patients in obtaining information from trusted sources and in establishing productive communication with other patients [16, 17]. Overall, although scores for productive interactions and patient self-management factors were generally satisfactory, scores for the new relational model factor were very low in all four subgroups of background disease. There are opportunities for improvement in current healthcare models, taking advantage of new technologies and communication channels and personalizing the approach according to patients' profiles and wishes [18]. In addition, less than one-third of patients received a regular follow-up call or visit after hospital discharge which, given the high percentage of patients who declared having been hospitalized, identifies a clear area for improvement.

Patients with rheumatic disease tended to have the lowest IEXPAC scores for overall patient experience and for each of factors $1-3$, whereas patients with HIV tended to have the highest scores. The latter finding suggests that the extent of personalized quality healthcare in patients with HIV may be greater than that in those with other chronic conditions (e.g., rheumatic disease) in Spain. This may be due to several reasons, including the prioritization and larger investment given several years ago to the care of patients living with HIV [19-21]. Potentially, if our findings are verified in other studies, then the quality of healthcare for patients with HIV can be used as an "aspirational standard" or requisite target level of healthcare quality to be attained in the management of other chronic illnesses.

Importantly, variables associated with better IEXPAC scores for overall patient experience, and the productive interactions, new relational model and patient self-management factors, were fewer specialist visits in the previous year, follow-up by the same rather than a different physician and fewer different medicines taken. Multivariate analysis revealed that overall IEXPAC scores for patient experience were significantly better when patients were followed-up by the same rather than a different physician, were followedup by a nurse, had healthcare help from others rather than relying on self-care and were treated with subcutaneous or intravenous drugs. This reflects the importance of nursing in the management of chronic diseases [22-26] and of simplifying patients' care by reducing the number of specialists seeing the patient. The fact that patients who were seen regularly by the same physician described better experiences suggests a level of emotional engagement and trust that can lower when the physician changes. In addition, patients with IBD, HIV infection or DM all had significantly better overall IEXPAC patient experience scores than patients with rheumatic disease.

As outlined, the IEXPAC instrument used in our survey has some advantages over traditionally used instruments such as the PACIC scale [8] and PCIC survey [9, 10]. IEXPAC focuses on patient interactions with healthcare teams 
Table 2 Responses to IEXPAC items

\begin{tabular}{|c|c|c|c|c|c|c|}
\hline \multirow[t]{2}{*}{ IEXPAC item } & \multicolumn{6}{|c|}{ Proportion of patients (\%) who responded "always" or "mostly" to each item } \\
\hline & $\begin{array}{l}\text { All patients } \\
(n=1618)\end{array}$ & $\begin{array}{l}\text { Rheumatic dis- } \\
\text { ease }(n=359)\end{array}$ & $\operatorname{IBD}(n=341)$ & HIV $(n=467)$ & $\mathrm{DM}(n=451)$ & $p$ value \\
\hline $\begin{array}{l}\text { 1. They respect my lifestyle. The professionals who care for me } \\
\text { listen to me and ask me about my needs, habits and preferences } \\
\text { to adapt my treatment and care plan }(n=1591)\end{array}$ & 81.5 & 76.5 & 75.1 & 89.6 & 81.9 & $<0.001$ \\
\hline $\begin{array}{l}\text { 2. They are coordinated to offer good healthcare to me. Health } \\
\text { and social care services are coordinated to improve my well- } \\
\text { being and quality of life in my environment (family, neighbor- } \\
\text { hood, town) }(n=1533)\end{array}$ & 69.3 & 60.6 & 61.9 & 76.8 & 73.3 & $<0.001$ \\
\hline $\begin{array}{l}\text { 3. They help me to get information from the internet. The } \\
\text { professionals who care for me inform me about trustful web } \\
\text { pages and internet forums that I can consult to better know my } \\
\text { disease, its treatment, and possible consequences on my life } \\
(n=1531)\end{array}$ & 15.0 & 12.8 & 19.0 & 19.8 & 8.3 & $<0.001$ \\
\hline $\begin{array}{l}\text { 4. Now I can take care of myself better. I feel that my confi- } \\
\text { dence in my ability to take care of myself, manage my health } \\
\text { problems and keep my autonomy has improved }(n=1529)\end{array}$ & 81.0 & 74.3 & 79.3 & 89.7 & 78.3 & $<0.001$ \\
\hline $\begin{array}{l}\text { 5. They ask me and help me to follow my treatment plan. I } \\
\text { regularly review adherence to my treatment and care plan with } \\
\text { the professionals who care for me }(n=1534)\end{array}$ & 79.8 & 73.5 & 77.8 & 87.6 & 78.2 & $<0.001$ \\
\hline $\begin{array}{l}\text { 6. We set goals for a healthy life and better control my illness. } \\
\text { I've been able to agree with the professionals who care for me } \\
\text { about specific objectives for diet, physical exercise and medica- } \\
\text { tion to get better control of my health problems }(n=1536)\end{array}$ & 70.1 & 63.4 & 62.6 & 74.7 & 76.1 & $<0.001$ \\
\hline $\begin{array}{l}\text { 7. I can use the internet and my mobile phone to consult my } \\
\text { medical records. I can consult my clinical records, test results, } \\
\text { programmed visits, and access other services through the inter- } \\
\text { net or mobile app of my health service }(n=1521)\end{array}$ & 7.2 & 7.3 & 5.5 & 8.6 & 7.1 & 0.529 \\
\hline $\begin{array}{l}\text { 8. They make sure that I take medication correctly. The pro- } \\
\text { fessionals who care for me review with me all of the medication } \\
\text { I take, how I take it, and how it suits me }(n=1543)\end{array}$ & 76.0 & 72.4 & 73.7 & 83.5 & 72.9 & $<0.001$ \\
\hline $\begin{array}{l}\text { 9. They worry about my welfare. The professionals who care } \\
\text { for me are concerned with my quality of life, and I feel they are } \\
\text { committed to my well-being }(n=1547)\end{array}$ & 84.3 & 79.1 & 80.4 & 91.5 & 83.8 & $<0.001$ \\
\hline $\begin{array}{l}\text { 10. I have been informed about health and social resources } \\
\text { that can help me. The professionals who care for me inform } \\
\text { me about the health and social resources available in my neigh- } \\
\text { borhood or town that I can use to improve my health problems } \\
\text { and take better care of myself }(n=1515)\end{array}$ & 41.3 & 33.8 & 32.3 & 52.6 & 42.3 & $<0.001$ \\
\hline $\begin{array}{l}\text { 11. They encourage me to talk to other patients. The profes- } \\
\text { sionals who care for me invite me to participate in patient } \\
\text { groups to share information and experiences about how to care } \\
\text { for ourselves and improve our health }(n=1513)\end{array}$ & 14.9 & 10.3 & 15.7 & 20.4 & 12.0 & $<0.001$ \\
\hline $\begin{array}{l}\text { Respond to the following statement only if you have been admit- } \\
\text { ted to hospital in the last } 3 \text { years: }\end{array}$ & & & & & & \\
\hline $\begin{array}{l}\text { 12. They care about me when I come home after being in } \\
\text { hospital. After hospital discharge, they called or visited me at } \\
\text { home to see how I was and what care I needed }(n=780)\end{array}$ & 30.6 & 25.7 & 28.9 & 33.0 & 32.8 & 0.205 \\
\hline
\end{tabular}

$D M$ diabetes mellitus, HIV human immunodeficiency virus, IBD inflammatory bowel disease, IEXPAC Instrument for Evaluation of the Experience of Chronic Patients

and other patients and also includes aspects of social care, patient self-management and technologic innovation [2]. Nevertheless, our study had some limitations. As this was an anonymous survey, we do not know the patient profiles of those who did not return the survey or their reasons for not responding. In general, these kinds of voluntary surveys tend to generate responses more frequently from motivated patients or patients who are particularly worried about their health. The consecutive inclusion of patients reduces selection bias but does not eliminate it: patients with more severe conditions, who are seen more frequently, are more likely to be invited to participate. However, it is this population who will potentially benefit more from any improvements implemented in the healthcare system. Also, study outcomes refer to specific patients' profiles. On one hand, these are not representative of the overall population of patients with 


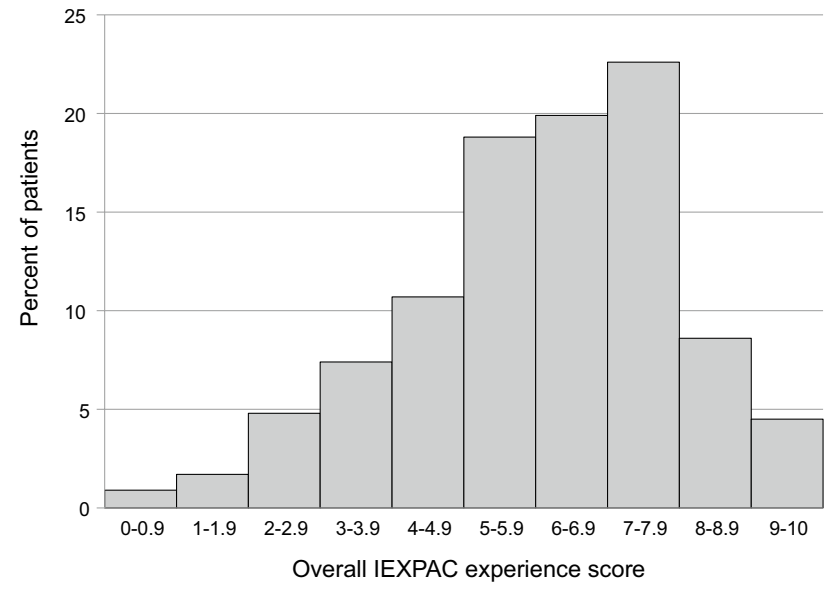

Fig. 2 Frequency distribution of overall Instrument for Evaluation of the Experience of Chronic Patients (IEXPAC) experience scores chronic conditions; on the other hand, the specific outcomes of each population deserve future study. Although the multivariate models explained only a small part of the variability, factors were identified that, if corrected, have the potential to improve healthcare quality and patient experience. To the best of our knowledge, this is the first study to evaluate factors related to better patient experience as measured by the IEXPAC, so future studies should be conducted to confirm our findings. Further, definitive data are lacking about whether IEXPAC score improvements are linked directly with improvements in clinical effectiveness and healthrelated quality of life. The situation also arises that different scales may be needed to adequately assess healthcare quality for patients with chronic diseases in different care settings, such as patients in nursing home programs or patients assisted by caregivers. Nor does the IEXPAC scale permit

Table 3 IEXPAC experience scores: Overall scores and scores for the different factors

\begin{tabular}{|c|c|c|c|c|c|c|}
\hline & $\begin{array}{l}\text { All patients } \\
(n=1618)\end{array}$ & $\begin{array}{l}\text { Rheumatic dis- } \\
\text { ease }(n=359)\end{array}$ & $\operatorname{IBD}(n=341)$ & HIV $(n=467)$ & $\mathrm{DM}(n=451)$ & $p$ value \\
\hline Overall IEXPAC experience score & $6.0 \pm 1.9$ & $5.5 \pm 2.0$ & $5.9 \pm 2.0$ & $6.6 \pm 1.7$ & $5.9 \pm 1.9$ & $<0.001$ \\
\hline Productive interactions (factor 1) & $8.0 \pm 2.2$ & $7.5 \pm 2.5$ & $7.7 \pm 2.7$ & $8.6 \pm 1.8$ & $7.9 \pm 2.1$ & $<0.001$ \\
\hline New relational model (factor 2 ) & $2.0 \pm 2.3$ & $1.7 \pm 2.2$ & $2.2 \pm 2.2$ & $2.4 \pm 2.5$ & $1.7 \pm 2.0$ & $<0.001$ \\
\hline Patient self-management (factor 3) & $7.1 \pm 2.3$ & $6.5 \pm 2.5$ & $6.7 \pm 2.4$ & $7.8 \pm 2.0$ & $7.1 \pm 2.6$ & $<0.001$ \\
\hline
\end{tabular}

Data are presented as mean \pm standard deviation

$D M$ diabetes mellitus, $H I V$ human immunodeficiency virus, IBD inflammatory bowel disease, IEXPAC Instrument for Evaluation of the Experience of Chronic Patients

Table 4 Bivariate analysis: variables associated with better IEXPAC experience scores

\begin{tabular}{|c|c|c|c|c|}
\hline & $\begin{array}{l}\text { Overall IEXPAC } \\
\text { experience score }\end{array}$ & $\begin{array}{l}\text { Productive interac- } \\
\text { tions score (factor } \\
\text { 1) }\end{array}$ & $\begin{array}{l}\text { New relational } \\
\text { model score (fac- } \\
\text { tor } 2 \text { ) }\end{array}$ & $\begin{array}{l}\text { Patient self- } \\
\text { management score } \\
\text { (factor 3) }\end{array}$ \\
\hline Age & - & - & Lower age $^{a}$ & - \\
\hline Sex & Male & Male & - & Male \\
\hline Educational level achieved & - & Lower $^{\mathrm{a}}$ & Higher $^{\mathrm{a}}$ & Lower $^{\mathrm{a}}$ \\
\hline Barthel index 0-80 (vs. > 80) & - & - & - & - \\
\hline $\begin{array}{l}\text { Follow-up in a region different from home region (vs. same } \\
\text { region) }\end{array}$ & Different region & - & Different region & Different region \\
\hline Number of specialists visited in the past year & Lower $^{\mathrm{a}}$ & Lower $^{\mathrm{a}}$ & Lower $^{\mathrm{a}}$ & Lower $^{\mathrm{a}}$ \\
\hline Being followed-up by the same vs. a different physician & Same physician & Same physician & Same physician & Same physician \\
\hline Follow-up by a nurse (vs. no nurse follow-up) & Follow-up by nurse & Follow-up by nurse & - & Follow-up by nurse \\
\hline $\begin{array}{l}\text { Receiving support from others for healthcare (vs. only } \\
\text { self-care) }\end{array}$ & - & - & - & - \\
\hline Number of different medicines taken & Lower $^{\mathrm{a}}$ & Lower $^{\mathrm{a}}$ & Lower $^{\mathrm{a}}$ & Lower $^{\mathrm{a}}$ \\
\hline Treatment with SC/IV drugs (vs. no SC/IV treatment) & - & - & - & - \\
\hline
\end{tabular}

See Electronic Supplementary Material 4-13 for more information

The table displays values for variables associated with better experience scores in the bivariate analysis $(p<0.05)$

IEXPAC Instrument for Evaluation of the Experience of Chronic Patients, $I V$ intravenous, $S C$ subcutaneous

${ }^{\mathrm{a}}$ Denotes linear trend 
Table 5 Multivariate analysis: Multiple logistic regression models for IEXPAC overall experience scores and different factor scores

Overall experience score Factor 1 (productive Factor 2 (new relational model) Factor 3 (patient selfinteractions)

management)

\begin{tabular}{|c|c|c|c|c|}
\hline Sex (female vs. male) & $-0.09 \pm 0.12(0.444)$ & $-0.15 \pm 0.14(0.298)$ & $-0.17 \pm 0.15(0.257)$ & $0.01 \pm 0.15(0.950)$ \\
\hline Age (per year of increment) & $-0.01 \pm 0.05(0.461)$ & $0.00 \pm 0.00(0.977)$ & $-0.02 \pm 0.01(0.004)$ & $0.01 \pm 0.01(0.486)$ \\
\hline $\begin{array}{l}\text { Educational level achieved (university } \\
\text { or further) }\end{array}$ & $0.01 \pm 0.8(0.966)$ & $-0.13 \pm 0.09(0.175)$ & $0.41 \pm 0.10(<0.001)$ & $-0.18 \pm 0.10(0.185)$ \\
\hline Barthel index 0-80 (vs. $>80$ ) & $0.13 \pm 0.22(0.547)$ & $0.05 \pm 0.25(0.834)$ & $0.04 \pm 0.26(0.871)$ & $0.42 \pm 0.26(0.108)$ \\
\hline $\begin{array}{l}\text { Follow-up in a region different from } \\
\text { home region (vs. same region) }\end{array}$ & $-0.29 \pm 0.23(0.216)$ & $-0.05 \pm 0.27(0.870)$ & $-0.56 \pm 0.28(0.049)$ & $-0.25 \pm 0.29(0.373)$ \\
\hline $\begin{array}{l}\text { Number of specialists visited in the } \\
\text { past year (per unit of increment) }\end{array}$ & $-0.09 \pm 0.03(0.002)$ & $-0.11 \pm 0.03(0.002)$ & $-0.04 \pm 0.04(0.258)$ & $-0.11 \pm 0.04(0.002)$ \\
\hline $\begin{array}{l}\text { Followed-up by the same vs. different } \\
\text { physician }\end{array}$ & $0.68 \pm 0.12(<0.001)$ & $0.94 \pm 0.14(<0.001)$ & $0.18 \pm 0.14(0.192)$ & $0.79 \pm 0.14(<0.001)$ \\
\hline $\begin{array}{l}\text { Followed-up by a nurse (vs. no nurse } \\
\text { follow-up) }\end{array}$ & $0.45 \pm 0.13(<0.001)$ & $0.35 \pm 0.15(0.019)$ & $0.60 \pm 0.15(<0.001)$ & $0.46 \pm 0.15(0.002)$ \\
\hline $\begin{array}{l}\text { Receiving support from others for } \\
\text { healthcare (vs. only self-care) }\end{array}$ & $0.28 \pm 0.13(0.026)$ & $0.19 \pm 0.15(0.198)$ & $0.34 \pm 0.15(0.029)$ & $0.33 \pm 0.15(0.034)$ \\
\hline $\begin{array}{l}\text { Number of different medicines taken } \\
\text { (per unit of increment) }\end{array}$ & $-0.03 \pm 0.08(0.140)$ & $-0.05 \pm 0.03(0.072)$ & $-0.01 \pm 0.03(0.806)$ & $-0.02 \pm 0.03(0.575)$ \\
\hline $\begin{array}{l}\text { Treatment with SC/IV drugs (vs. no } \\
\text { SC/IV treatment) }\end{array}$ & $0.43 \pm 0.14(0.002)$ & $0.59 \pm 0.16(<0.001)$ & $0.16 \pm 0.17(0.339)$ & $0.47 \pm 0.17(0.005)$ \\
\hline \multicolumn{5}{|l|}{ Background disease } \\
\hline IBD (vs. rheumatic disease) & $0.33 \pm 0.18(0.072)$ & $0.33 \pm 0.22(0.124)$ & $0.32 \pm 0.22(0.149)$ & $0.25 \pm 0.22(0.258)$ \\
\hline $\begin{array}{l}\text { HIV infection (vs. rheumatic } \\
\text { disease) }\end{array}$ & $1.31 \pm 0.19(<0.001)$ & $1.37 \pm 0.22(<0.001)$ & $0.81 \pm 0.22(<0.001)$ & $1.57 \pm 0.22(<0.001)$ \\
\hline DM (vs. rheumatic disease) & $0.62 \pm 0.20(0.002)$ & $0.73 \pm 0.24(0.002)$ & $0.24 \pm 0.25(0.325)$ & $0.62 \pm 0.24(0.012)$ \\
\hline
\end{tabular}

Data are presented as $\beta$ coefficients \pm standard deviation ( $p$ value)

$\beta$ coefficients indicate how much the IEXPAC score modifies with each variable versus its reference. Positive $\beta$ coefficients indicate that the variable is associated with higher IEXPAC experience scores with regard to its reference

Goodness of fit $\left(R^{2}\right)$ : overall experience score: 0.121; factor 1: 0.115; factor 2: 0.067; factor 3: 0.116

$H I V$ human immunodeficiency virus, IBD inflammatory bowel disease, IEXPAC Instrument for Evaluation of the Experience of Chronic Patients, $I V$ intravenous, $S C$ subcutaneous, $S D$ standard deviation

allocation of healthcare responsibilities to individual healthcare providers; rather, it directs such responsibilities toward healthcare teams or healthcare systems [2].

\section{Conclusions}

This cross-sectional survey utilized the IEXPAC scale and involved a large sample of patients with chronic conditions (DM, HIV infection, IBD or rheumatic disease). The study clearly demonstrated that marked potential exists for healthcare quality improvements regarding helping patients to get information from the internet, to access medical records via mobile phone and internet and to communicate with other patients. The importance of follow-up by the same physician, as well as nurse follow-up, for enhancing healthcare quality were also emphasized, as was the significance of patients receiving help from others rather than adopting selfcare. Overall, use of the IEXPAC instrument has not yet been adopted universally in routine practice. However, IEXPAC assessment of the experiences of chronically ill patients may clearly redirect healthcare toward more patient-centered healthcare goals while facilitating integrated improvements in social care and long-term healthcare quality.

Acknowledgements This study was funded by Merck Sharp \& Dohme (MSD), Spain, a subsidiary of Merck and Co., Kenilworth, NJ, USA. The study was reviewed and endorsed by the following patients' associations: CONARTRITIS, ACCU and FEDE, and by SEISIDA. The authors thank all patients who completed the survey, the IEXPAC working group for providing the valuable tool, and Professor José Joaquín Mira for his recommendations and critical review. The authors thank David Murdoch and David P. Figgitt, Ph.D., ISMPP CMPPTM, Content Ed Net, for their writing and editorial assistance in the preparation of this manuscript, with funding from MSD Spain.

Author contributions Domingo Orozco-Beltrán, Javier de Toro, María J. Galindo, Ignacio Marín-Jiménez, Gonzalo Fernández, Nuria Sánchez-Vega and Luis Cea-Calvo participated in the design and implementation of the study. Luis Cea-Calvo assumed primary responsibility for writing the manuscript. The rest of the authors also made 
substantial contributions to the manuscript, and all authors approved the final version.

Data availability The data that support the findings of this study are available from the corresponding author upon reasonable request.

\section{Compliance with Ethical Standards}

Funding This project was funded by Merck Sharp and Dohme, Spain.

Conflict of interest Domingo Orozco-Beltrán has provided consultancy services to MSD and Novartis and has lectured for Novartis, Mundipharma, Novo, Sanofi Aventis and Lilly. María J. Galindo has provided consultancy services to Viiv, Abbie, MSD, Gilead and Janssen; her institution has received grants from MSD, Janssen and Gilead and payments for travel to meetings from MSD and for lectures or educational presentations from MSD, Janssen, Gilead and Viiv. Ignacio Marín-Jiménez has received research funding (to his institution) and payment for acting as a consultant, advisory member or speaker from AbbVie, Chiesi, Faes Farma, Falk-Pharma, Ferring, Gebro Pharma, Hospira, Janssen, MSD, Otsuka Pharmaceutical, Pfizer, Shire, Takeda, Tillots and UCB Pharma. Francesc Casellas has received research funding (to his institution) from AbbVie, MSD, Shire, Ferring and Zambon and speaker fees from AbbVie, MSD, Shire, Ferring and Zambon. María J. Fuster-RuizdeApodaca has received research funding (to her institution) from ViiV Healthcare, MSD, Janssen and Gilead and payments for consultancy services (to her institution) from Gilead, ViiV Healthcare and Janssen and for lectures (to her institution) from Gilead and ViiV Healthcare. María L. García-Vivar has provided consultancy services to MSD, BMS and Janssen and expert testimony for AbbVie and Pfizer and has received grants (to her institution) from Roche, MSD and UCB and payments for lectures from Novartis, GSK, Celgene, Lilly, Janssen, AbbVie and Pfizer. Mercedes Guilabert has received consultancy and travel/meeting expenses from MSD. Nuria Sánchez-Vega, Gonzalo Fernández and Luis Cea-Calvo are full-time employees of MSD Spain. Javier de Toro and Antonio Hormigo-Pozo have no conflicts of interest that are directly related to the content of this article.

Open Access This article is distributed under the terms of the Creative Commons Attribution-NonCommercial 4.0 International License (http://creativecommons.org/licenses/by-nc/4.0/), which permits any noncommercial use, distribution, and reproduction in any medium, provided you give appropriate credit to the original author(s) and the source, provide a link to the Creative Commons license, and indicate if changes were made.

\section{References}

1. Doyle C, Lennox L, Bell D. A systematic review of evidence on the links between patient experience and clinical safety and effectiveness. BMJ Open. 2013;3(1):e001570.

2. Mira JJ, Nuno-Solinis R, Guilabert-Mora M, et al. Development and validation of an instrument for assessing patient experience of chronic illness care. Int J Integr Care. 2016;16(3):13.

3. Coleman K, Austin BT, Brach C, Wagner EH. Evidence on the chronic care model in the new millennium. Health Aff (Millwood). 2009;28(1):75-85.

4. Martinez-Gonzalez NA, Berchtold P, Ullman K, et al. Integrated care programmes for adults with chronic conditions: a metareview. Int J Qual Health Care. 2014;26(5):561-70.
5. Davy C, Bleasel J, Liu H, et al. Effectiveness of chronic care models: opportunities for improving healthcare practice and health outcomes: a systematic review. BMC Health Serv Res. 2015;15:194.

6. Rathert C, Huddleston N, Pak Y. Acute care patients discuss the patient role in patient safety. Health Care Manag Rev. 2011;36(2):134-44.

7. Cramm JM, Nieboer AP. High-quality chronic care delivery improves experiences of chronically ill patients receiving care. Int J Qual Health Care. 2013;25(6):689-95.

8. Glasgow RE, Wagner EH, Schaefer J, et al. Development and validation of the Patient Assessment of Chronic Illness Care (PACIC). Med Care. 2005;43(5):436-44.

9. Singer SJ, Friedberg MW, Kiang MV, et al. Development and preliminary validation of the Patient Perceptions of Integrated Care survey. Med Care Res Rev. 2013;70(2):143-64.

10. Singer SJ, Burgers J, Friedberg M, et al. Defining and measuring integrated patient care: promoting the next frontier in health care delivery. Med Care Res Rev. 2011;68(1):112-27.

11. Vrijhoef HJ, Berbee R, Wagner EH, Steuten LM. Quality of integrated chronic care measured by patient survey: identification, selection and application of most appropriate instruments. Health Expect. 2009;12(4):417-29.

12. Berwick DM, Nolan TW, Whittington J. The triple aim: care, health, and cost. Health Aff (Millwood). 2008;27(3):759-69.

13. Shah S, Vanclay F, Cooper B. Improving the sensitivity of the Barthel Index for stroke rehabilitation. J Clin Epidemiol. 1989;42(8):703-9.

14. Bos-Touwen I, Schuurmans M, Monninkhof EM, et al. Patient and disease characteristics associated with activation for selfmanagement in patients with diabetes, chronic obstructive pulmonary disease, chronic heart failure and chronic renal disease: a cross-sectional survey study. PLoS One. 2015;10(5):e0126400.

15. Fan J, McCoy RG, Ziegenfuss JY, et al. Evaluating the structure of the Patient Assessment of Chronic Illness Care (PACIC) survey from the patient's perspective. Ann Behav Med. 2015;49(1):104-11.

16. Smith D. Health care consumer's use and trust of health information sources. J Commun Healthc. 2011;4(3):200-10.

17. Fage-Butler AM, Nisbeth Jensen M. Medical terminology in online patient-patient communication: evidence of high health literacy? Health Expect. 2016;19(3):643-53.

18. Househ M. The use of social media in healthcare: organizational, clinical, and patient perspectives. Stud Health Technol Inform. 2013;183:244-8.

19. Schwartländer B, Stover J, Hallett T, et al. Towards an improved investment approach for an effective response to HIV/AIDS. Lancet. 2011;377(9782):2031-41.

20. Stover J, Hallett TB, Wu Z, et al. How can we get close to zero? The potential contribution of biomedical prevention and the investment framework towards an effective response to HIV. PLoS One. 2014;9(11):e111956.

21. Stover J, Bollinger L, Izazola JA, et al. What is required to end the AIDS epidemic as a public health threat by 2030? The cost and impact of the Fast-Track approach. PLoS One. 2016;11(5):e0154893.

22. Nightingale AJ, Middleton W, Middleton SJ, Hunter JO. Evaluation of the effectiveness of a specialist nurse in the management of inflammatory bowel disease (IBD). Eur J Gastroenterol Hepatol. 2000;12(9):967-73.

23. Bodenheimer T, MacGregor K, Stothart N. Nurses as leaders in chronic care: their role is pivotal in improving care for chronic diseases. BMJ. 2005;330(7492):612-3.

24. Davidson PM, De Geest S, Hill MN. Nurses addressing the challenges of chronic illness: from primary to palliative care. Collegian. 2010;17(2):43-5. 
25. Hernández-Sampelayo $\mathrm{P}$, Seoane M, Oltra L, et al. Contribution of nurses to the quality of care in management of inflammatory bowel disease: a synthesis of the evidence. J Crohns Colitis. 2010;4(6):611-22.
26. Coates V. Role of nurses in supporting patients to self-manage chronic conditions. Nurs Stand. 2017;31(38):42-6.

\section{Affiliations}

Domingo Orozco-Beltrán ${ }^{1} \cdot$ Javier de Toro $^{2} \cdot$ María J. Galindo $^{3} \cdot$ Ignacio Marín-Jiménez ${ }^{4} \cdot$ Francesc Casellas $^{5}$. María J. Fuster-RuizdeApodaca ${ }^{6}$ - María L. García-Vivar ${ }^{7}$. Antonio Hormigo-Pozo ${ }^{8}$. Mercedes Guilabert ${ }^{9}$. Nuria Sánchez-Vega ${ }^{10} \cdot$ Gonzalo Fernández $^{10} \cdot$ Luis Cea-Calvo $^{10}$

1 Clinical Medicine Department, Miguel Hernandez University, San Juan de Alicante, Spain

2 Rheumatology Department, A Coruña University Hospital, A Coruña, Spain

3 Clinic University Hospital, Valencia, Spain

4 IBD Unit, Gastroenterology Department, Clinical Research Institute Gregorio Marañón (IiSGM), Gregorio Marañón University, Madrid, Spain

5 Crohn-Colitis Care Unit, Hospital Universitari Vall d'Hebron, Barcelona, Spain
6 SEISIDA (Spanish AIDS Multidisciplinary Society), Madrid, Spain

7 Rheumatology Department, Basurto University Hospital, Bilbao, Spain

8 San Andres-Torcal Health Care Center, Málaga, Spain

9 Department of Health Psychology, Miguel Hernández University, Elche, Alicante, Spain

10 Medical Affairs Department, Merck Sharp and Dohme Spain, Madrid, Spain 